and since amount of release did not increase with fluency, once a moderate amount of fluency was present, it is unreasonable to conclude that the minor amount of release found in this experiment is attributable to the Ss' inability to identify gender.

The present data are generally in accord with Wickens's (1972) classification of stimulus dimensions on the basis of the amount of release produced by a shift on those dimensions. The amount of PI release is somewhat greater for a change in gender than for changes in other marking-syntactic dimensions, but is small relative to the amount of release found for other kinds of shifts. It appears, therefore, that word gender is not a particularly salient encoding dimension.

\section{REFERENCES}

Keppel, G., \& Underwood, B. J. Proactive inhibition in short-term retention of single items. Journal of Verbal Learning \& Verbal Behavior, 1962, 1, 153-161.

Wickens, D. D. Characteristics of word encoding. In A. W. Melton and E. Martin (Eds.), Coding processes in human memory. New York: Winston-Wiley, 1972.

Wickens, D. D., Born, D. G., \& Allen, C. K. Proactive inhibition and item similarity in short-term memory. Journal of Verbal Learning \& Verbal Behavior, 1963, 2, 440-445.

(Received for publication December 5, 1973.)

\title{
Trace and delay differential classical eyelid conditioning in human adults*
}

\author{
SUSAN M. ROSS $\dagger$, LEONARD E. ROSS, and DEBORAH WERDEN \\ University of Wisconsin-Madison, Madison, Wisconsin 53706
}

\begin{abstract}
Experiment I compared trace and delay differential classical eyelid conditioning in adult human Ss at three ISIs $(800,1,100,1,400 \mathrm{msec})$. Pure-tone CSs were used, with the trace CS having a duration of $50 \mathrm{msec}$ and the delay CS terminating with the UCS. There was no significant trace deficit at any ISI, which indicates that the recognition or identification response involved in the differential classical conditioning of adult humans is maintained during long trace-stimulus offset to UCS-onset intervals. Experiment II compared trace and delay differential conditioning at 300-, 500-, and 800-msec ISIs. Again there was no trace conditioning deficit. Differential conditioning was significantly poorer at a 500 than at an 800-msec ISI, and no differential conditioning was found with a 300-msec ISI. The level of conditioning of the 300 -msec group was much below that of the other groups and that expected for single-cue conditioning at the same ISI.
\end{abstract}

It has been established that trace and delay classical conditioning procedures are equally effective for the single-cue classical eyelid conditioning of normal adults. A comparison of the data of several early trace and delay conditioning studies leads to this conclusion, and a more recent study (Ross \& Ross, 1971) has clearly demonstrated equal trace and delay conditioning performance across a wide range of interstimulus intervals (ISIs).

In contrast to these trace-delay comparisons of single-cue conditioning, there does not appear to be any research which has systematically investigated the

\footnotetext{
*This research was supported by PHS Grant HD 05653. The authors thank Joyce B. Reinhardt for her help in collecting the data of Experiment II.

tRequests for reprints should be sent to $S$. M. Ross, Department of Psychology, University of Wisconsin, Madison, Wisconsin 53706.
}

relative effectiveness of trace and delay CSs in differential classical eyelid conditioning. Given the fact that additional stimulus recognition and response requirements are involved in differential conditioning (e.g., Ross \& Nelson, 1973), it might be expected that trace-delay differences would be found in differential conditioning, especially with ISIs where a relatively long interval intervenes between the offset of the trace CS and the onset of the UCS. Accordingly, Experiment I compared trace and delay differential conditioning at ISIs of $800,1,100$, and $1,400 \mathrm{msec}$, the shortest of which was found by Hartman and Grant (1962) to be optimal for delay differential eyelid conditioning.

\section{EXPERIMENT I}

\author{
Method \\ Subjects and Apparatus. The Ss were 96 college students
}




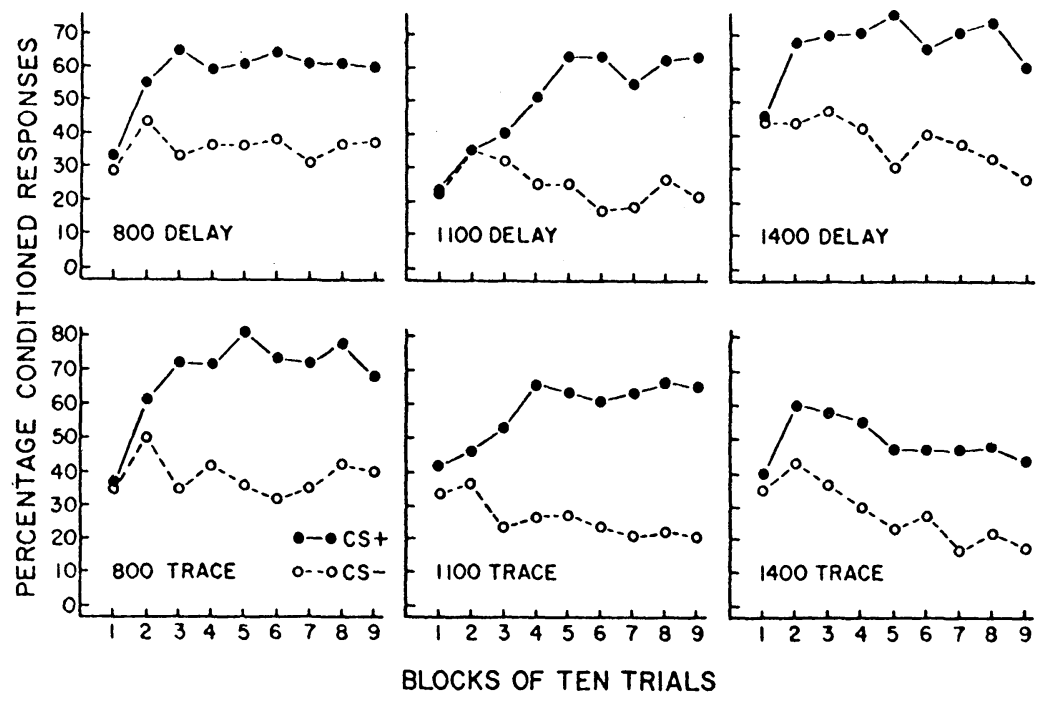

Fig. 1. Mean percentage responding to $\mathrm{CS}+$ and $\mathrm{CS}$ - as a function of trace vs delay CS and ISI in Experiment I.

enrolled in introductory psychology courses at the University of Wisconsin. Extra-credit "experimental points" were awarded to the Ss for their participation. The Ss were assigned at random to the experimental groups with the restriction that each group contain half males and half females.

The experiment was conducted in a 3-room laboratory. One $\mathrm{S}$ was tested in each of two experimental rooms, which contained an ophthalmologist's chair for $S$ and movie projecting equipment. The $\mathrm{E}$ monitored the stimulus-generating equipment and recording polygraph in a third room.

Earphones were used to present a $65-\mathrm{dB}$ white noise background and the two pure-tone CSs $(800$ and $2,100 \mathrm{~Hz})$, which were matched in loudness to a $1,000-\mathrm{Hz}$ tone with an intensity of $85 \mathrm{~dB}$ (see Wilcox \& Ross, 1969, for exact specifications of these stimuli). All tones had a fast rise and decay time $(\approx 10$ microsec). The trace CS had a duration of $50 \mathrm{msec}$, and the delay CS terminated with UCS offset. For both conditions, the ISI was measured from the onset of the CS to the onset of the UCS. The UCS was a .75-psi puff of compressed air of $100-\mathrm{msec}$ duration delivered to the right cornea. Intertrial intervals of 15,20 , and $25 \mathrm{sec}$, with a mean of $20 \mathrm{sec}$, were employed.

Design and Procedure. The design for this experiment was a 3 by 2 by 2 by 2 factorial including three ISIs $(800,1,100$, and $1,400 \mathrm{msec}$ ), two CS durations (trace and delay), two CS+ frequencies ( 800 and $2,100 \mathrm{~Hz}$ ), and sex of $S$.

The $S$ was seated in the experimental room and then told that the $\mathrm{E}$ was interested in his reactions to certain events as these events occurred while he was watching a silent motion picture. The headset and earphones were placed on S's head and the headrest adjusted. Further instructions were then presented to the $S$ through the earphones. The $S$ was requested not to touch any of the equipment on his head at any time, to relax and watch the movie, and try not to aid or inhibit any of his natural responses. The S was presented one CS+ alone trial, one CSalone trial, and one UCS-alone trial, and was told that events like these would occur during the silent movie. The film was then started. Each session consisted of 90 differential conditioning trials. There were 45 positive and 45 negative trials presented in a Gellerman sequence which repeated every 30 trials and which contained $5 \mathrm{CS}+$ and $5 \mathrm{CS}$ - trials in each 10-trial block.

\section{Results}

The first $2-\mathrm{mm}$ pen deflection ( $1 \mathrm{~mm}$ at the eye) occurring in the interval from $200 \mathrm{msec}$ after CS onset to UCS onset was scored as a CR. Mean percentages of
CRs to CS+ and CS - for the three ISI trace and delay groups are shown in blocks of 10 trials in Fig. 1. Differences in responding to $\mathrm{CS}+$ and $\mathrm{CS}-$ during the last four trial blocks were analyzed in a 3 by 2 by 2 by 2 analysis of variance including the three ISIs, trace vs delay CS, CS+ frequency, and sex of S. Neither the main effect of the trace-delay variable nor ISI reached significance (both Fs $<1$ ) and none of the other main effects or interactions were significant at the .05 level.

There appears to be somewhat less differential conditioning under trace conditions at the $1,400-\mathrm{msec}$ ISI, but a $t$ test of the difference was not significant $(\mathrm{t}=$ $.68, \mathrm{df}=30, \mathrm{p}>.20)$.

\section{EXPERIMENT II}

Experiment II compared trace and delay differential conditioning at ISIs shorter than those used in Experiment I. Hartman and Grant (1962) found that differential conditioning was better at an 800 -msec ISI than at shorter ISIs, and it was of interest to attempt to replicate this finding and to examine possible trace-delay differences at ISIs which are optimal for single-cue conditioning but not for differential conditioning.

\section{Method and Results}

The Ss for Experiment II were 73 college students who were enrolled in introductory psychology courses and who received "experimental points" for their participation. The data of one $\mathrm{S}$ was lost due to apparatus failure. The remaining Ss were assigned to experimental groups randomly with the restriction that each group contain half males and half females. The apparatus, design, and procedure were identical to those of Experiment I, except for the ISTI values, which were 300,500 , and $800 \mathrm{msec}$.

Conditioned responses were defined as described in Experiment I. Average CR frequencies in blocks of 10 trials are shown in Fig. 2 as a function of the trace-delay 
Fig. 2. Mean percentage responding to $\mathrm{CS}+$ and $\mathrm{CS}-$ as a function of trace vs delay CS and ISI in Experiment II.

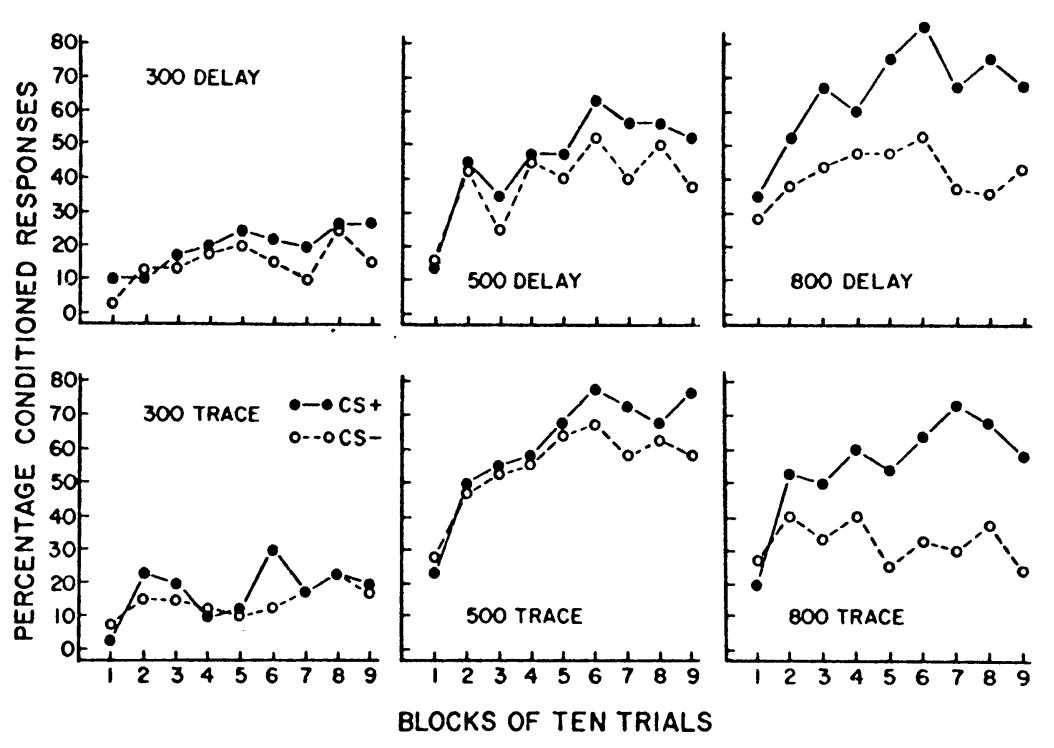

and the present results demonstrate the capability of normal adult Ss to retain the recognition information necessary for good differential conditioning across the same intervals. In contrast, the severely retarded do not show single-cue acquisition with a trace CS when the ISI is as short as $500 \mathrm{msec}$ (Ross, 1972).

The present study was concerned with the retention of differential stimulus information rather than the conditions necessary for the initial recognition response to the $\mathrm{CS}+$ or $\mathrm{CS}-$. If trace stimuli were so brief as to preclude recognition, differential conditioning would not be expected. Given the necessary initial information, however, that information apparently is retained across the ISI and leads to differential conditioning whether the original stimulus remains present or is absent.

The data of Experiment II replicate the finding of Hartman and Grant (1962) of superior differential conditioning with an 800 -msec ISI as compared to shorter ISIs. In addition, with a 300 -msec ISI there was no differential conditioning and the overall level of responding was very low. This low response level is surprising since single-cue conditioning at that ISI in the Ross and Ross (1971) study was much better with performance levels of $54.7 \%$ for trace conditioning and $46.2 \%$ for delay conditioning on Trials 41-80. These data suggest that some process operates to depress overall level of responding when differential conditioning does not occur under nonoptimal ISI conditions.

\section{REFERENCES}

Hartman, T. F., \& Grant, D. A. Differential eyelid conditioning as a function of the CS-UCS interval. Journal of Experimental Psychology, 1962, 64, 131-136.

Hartman, T. F. \& Ross, L. E. An alternative criterion for the elimination of "voluntary" responses in eyelid conditioning. Journal of Experimental Psychology, 1961, 61, 334-338.

Ross, L. E., \& Nelson, M. N. The role of awareness in differential conditioning. Psy chophysiology, 1973, 10, 91-94.

The results of Experiment I clearly show that the differential conditioning performance of adults is similar with trace and delay CSs. In this study, the relatively short $50-\mathrm{msec}$ trace CSs were as effective in providing the information necessary for differential responding as were the longer delay CSs that overlapped the UCS.

Assuming stimulus input is sufficient, conditioning with a trace CS presumably requires that the CS information be retained in some manner, e.g., as a stimulus trace, during the interval between the offset of the CS and the onset of the UCS. The single-cue conditioning data of Ross and Ross (1971) demonstrated that normal adults can do this with no decrement in conditioning performance with an ISI as long as $1,400 \mathrm{msec}$,
Ross, S. M. Trace and delay classical eyelid conditioning in severely and profoundly retarded subjects as a function of interstimulus interval. American Journal of Mental Deficiency, $1972,77,39-45$.

Ross, S. M., \& Ross, L. E. Comparison of trace and delay classical eyelid conditioning as a function of interstimulus interval. Journal of Experimental Psychology, 1971, 91, 165-167. conditioning as a function of $C S$ intensity, CS rise time, and interstimulus interval. Journal of Experimental Psychology, $1969,82,272-278$.

(Received for publication December 10, 1973.)
Wilcox, S. M., \& Ross, L. E. Differential classical eyelid 